\title{
Strategi Promosi UPT Perpustakaan UMM pada Masa Pandemi Covid-19
}

\author{
Dian Puspitasari* \\ Universitas Muhammadiyah Malang, Indonesia.
}

Article Info

Received April 1, 2021

Revised April 17, 2021

Accepted April 21, 2021

Keywords

- Promotion Strategy

- College Library

- Covid-19 Pandemic

- UPT UMM Library

\section{Abstract}

Introduction: The Covid-19 pandemic caused university libraries to adopt policies restricting small and large-scale activities, including UPT UMM Library. The outbreak required UPT UMM Library to change the routine of library services in normal time by adjusting library services during the pandemic. Therefore, it requires a strategic library promotion.

Methodology: The study employed descriptive method with qualitative approach. Data analysis techniques used Cresswell's descriptive qualitative analysis model.

Results: The result showed that promotional strategy conducted UMM Library during the Covid-19 pandemic are to create library programs consisting of user education, information literacy classes, seminars and book reviews. In addition, in collaboration with FPPTI of East Java and also FPPTMA, UMM Library created "myUMM Library" which communicates and serves library users though social medias.

Conclusion: As a result, the impact generated by the library promotion strategy during the pandemic has significant increase in digital visits and digital access.

\section{Pendahuluan}

Covid-19 pertama kali ditemukan pada bulan Desember 2019 di Cina dan penyebarannya sangat cepat ke berbagai negara, salah satunya Indonesia. Pandemi Covid19 menyebabkan suatu negara mengambil kebijakan adanya pembatasan kegiatan berskala kecil dan besar, sosial distancing hingga karantina. Hal tersebut dilakukan setidaknya dapat memutus rantai penyebaran Covid-19. Melihat kondisi pandemi Covid19 menimbulkan dampak dari berbagai sektor pariwisata, ekonomi, industri, bisnis, kesehatan, pendidikan, perpustakaan, tidak terkecuali perpustakaan perguruan tinggi. Perpustakaan perguruan tinggi ialah perpustakaan universitas yang menyediakan layanan, sumber daya dan jasa untuk mendukung kebutuhan pembelajaran, pengajaran, dan penelitian mahasiswa, pengajar, dan staf (Rosa \& Storey, 2016).

Unsur utama dalam pencapaian keberhasilan perpustakaan perguruan tinggi dalam menunjang Tri Dharma Perguruan Tinggi dapat dilihat dari layanan perpustakaan, hal ini dikarenakan layanan perpustakaan berhubungan langsung dengan pemustaka dalam penyebaran informasi serta pemanfaatan jasa dan fasilitas yang ada di perpustakaan. Rahayuningsih (2007) menyatakan layanan perpustakaan mengacu pada penggunaan layanan umum, layanan yang berorientasi pada pengguna, mudah digunakan, pengembangan yang cepat dan akurat dari prinsip-prinsip dasar mata pelajaran dan sistem untuk menyediakan layanan informasi kepada pengguna. Selain layanan perpustakaan sebagai unsur utama, koleksi, fasilitas, sarana dan prasarana juga

\footnotetext{
* Corresponding Author.

Email Address: dianpuspita0903@umm.ac.id
} 
merupakan hal yang penting di dalam sebuah perpustakaan. Beragamnya layanan, koleksi, fasilitas, sarana dan prasarana yang dimiliki perpustakaan, maka perlu adanya promosi perpustakaan.

Kegiatan promosi perpustakaan perguruan tinggi sangat perlu dilakukan, hal ini mengingat apresiasi nyata civitas akademika terhadap perpustakaan begitu rendah. Promosi menurut Mustafa (2012) adalah setiap kegiatan komunikasi yang bertujuan untuk memperkenalkan produk atau ide layanan melalui distribusi. Promosi adalah upaya penjual untuk membujuk orang lain agar menggunakan produk, layanan, atau ide yang dipromosikan. Singkatnya, promosi bertujuan untuk mempengaruhi sikap, pengetahuan atau perilaku penerima dan membujuk mereka untuk menerima konsep barang atau jasa. Promosi perpustakaan yang dilakukan tentunya membutuhkan strategi, agar promosi yang dilakukan berjalan sesuai dengan rencana dan hasil yang ingin dicapai.

Strategi promosi adalah kegiatan dirancang untuk mempengaruhi konsumen agar dapat memahami produk yang ditawarkan perusahaan, dan kemudian konsumen akan dengan senang hati membeli produk tersebut. Adapun alat yang dapat digunakan untuk promosi, pengusaha dapat memilih beberapa cara yaitu: (1) advertensi, (2) promosi penjualan (sales promotion), (3) kontak langsung (personal selling), (4) publisitas (publication) (Gitosudarmo, 2008). Sasaran promosi perpustakaan perguruan tinggi adalah civitas akademika perguruan tinggi yang dilayani, baik itu mahasiswa, dosen, peneliti, guru besar, pimpinan serta staf administrasi dan akademik.

UPT Perpustakaan Universitas Muhammadiyah Malang (UPT Perpustakaan UMM) merupakan salah satu perpustakaan perguruan tinggi swasta yang berada di Malang dan menjadi pusat sumber informasi bagi civitas akademika UMM. UPT Perpustakaan UMM dalam segi koleksi, layanan, fasilitas, sarana dan prasarana dapat dikatakan sudah baik dan semakin mendukung perannya di Universitas Muhammadiyah Malang, sehingga pada tahun 2019 UPT Perpustakaan UMM meraih Akreditasi “A”, No: 00110/LAP.PT/XI.2019 dari Perpustakaan Nasional Republik Indonesia (Olahan Penulis, 2021). UPT Perpustakaan UMM memiliki koleksi tercetak dan koleksi digital yang cukup banyak, diantaranya jumlah koleksi tercetak sejumlah 72.987 Judul, 215.549 Eksemplar dan koleksi digital sebanyak 12.100 Judul.

Selama masa pandemi Covid-19, UPT Perpustakaan UMM tetap membuka layanan, pemustaka dapat datang langsung ke perpustakaan dengan mematuhi protokoler kesehatan yang ada. Namun, antusias pemustaka tidak sebaik pada waktu normal, hal ini dapat dilihat dari menurunnya kunjungan di UPT Perpustakaan UMM pada masa pandemi (lihat Tabel 1).

Tabel 1 Statistik Pengunjung Perpustakaan Pada Saat Normal dan Pandemi Covid-19 di UPT Perpustakaan UMM

\begin{tabular}{llllll}
\hline $\begin{array}{l}\text { Pengunjung } \\
\text { Perpustakaan }\end{array}$ & $\begin{array}{l}\text { Bulan Desember } \\
2019\end{array}$ & $\begin{array}{l}\text { Bulan Januari-Maret } \\
2020\end{array}$ & $\begin{array}{l}\text { Bulan April- } \\
\text { Desember 2020 }\end{array}$ & $\begin{array}{l}\text { Bulan Januari- } \\
\text { Maret 2021 }\end{array}$ & Jumlah \\
\hline Normal & 16.937 & 34.701 & - & - & 51.638 \\
Pandemi & - & - & 14.630 & 8.298 & 22.928 \\
\hline \multicolumn{5}{r}{} & Sumber: http://otomasi.lib.umm.ac.id/admin/form-location/
\end{tabular}

Penurunan kunjungan UPT Perpustakaan UMM selama pandemi Covid-19 dikarenakan adanya pembatasan kegiatan mahasiswa di kampus dan kegiatan perkuliahan dapat dilakukan di rumah. UPT Perpustakaan UMM selain memberikan layanan informasi kepada pemustaka secara langsung, juga memberikan layanan informasi kepada mahasiswa yang melakukan kegiatan perkulihan di rumahnya masing-masing melalui layanan informasi online terkait koleksi buku maupun database e-resources yang di langgan perpustakaan. Pemenuhan kebutuhan penelusuran informasi yang dibutuhkan 
mahasiswa dan beberapa kegiatan literasi informasi perpustakaan dilakukan secara online. Adanya perubahan rutinitas yang dilakukan UPT Perpustakaan UMM pada masa pandemi Covid-2019 khususnya dalam hal layanan perpustakaan, maka diperlukan adanya strategi promosi perpustakaan. Hal ini dilakukan agar keinginan dan kebutuhan informasi pemustaka tetap terpenuhi secara prima dan maksimal.

Tulisan ini menggali bagaimana strategi promosi UPT Perpustakaan UMM pada masa pandemi Covid-19 dan tujuan yang ingin dicapai adalah menganalisis strategi promosi UPT Perpustakaan UMM pada masa pandemi Covid-19.

\section{Tinjauan Pustaka}

\subsection{Perpustakaan Perguruan Tinggi}

Perpustakaan perguruan tinggi adalah perpustakaan yang berada di bawah naungan perguruan tinggi dan memberikan layanan kepada semua sarjana pendidikan tinggi, termasuk mahasiswa, dosen, peneliti, profesor, pemimpin dan administrator, untuk mendukung Tri Dharma Perguruan Tinggi (Martoatmojo, 2011). Tujuan perpustakaan perguruan tinggi menurut Qalyubi (2007) adalah memenuhi kebutuhan informasi dosen dan mahasiswa, memberikan referensi bahan pustaka di berbagai jenjang akademik, menyediakan ruang bagi pengunjung, memberikan layanan peminjaman, dan menyediakan layanan informasi aktif bagi pengunjung.

Layanan perpustakaan menurut Departemen Pendidikan Nasional (2004) adalah pemberian informasi dan fasilitas kepada pemustaka. Secara singkat perpustakaan perguruan tinggi merupakan perpustakaan yang berada pada suatu perguruan tinggi yang memberikan layanan informasi dan fasilitas kepada civitas akademika dalam menunjang Tri Dharma Perguruan Tinggi dan dapat memenuhi keinginan dan kebutuhan pemustaka.

\subsection{Promosi Perpustakaan}

Promosi adalah memperkenalkan bentuk komunikasi produk kepada pengguna dan calon pengguna (costumer) agar mau membeli dan menggunakannya (Harsana, 2005), sedangkan menurut Gitosudarmo (2008) promosi adalah bagaimana cara mempengaruhi konsumen agar memahami produk yang ditawarkan oleh perusahaan dan kemudian konsumen tertarik untuk membeli produk tersebut. Secara singkat promosi perpustakaan adalah bentuk komunikasi yang dilakukan perpustakaan untuk memperkenalkan layanan perpustakaan agar pemustaka sapat memanfaatkannya secara efektif dan efisien sesuai dengan keinginan dan kebutuhan informasi pemustaka.

Banyak kegiatan promosi yang dapat diterapkan di perpustakaan menurut Mustafa (2012) sebagai berikut: pemasaran, promosi, periklanan, publikasi dan hubungan masyarakat. Kemudian menurut teori umum promosi dan pemasaran perpustakaan akan dikaitkan dengan kegiatan atau layanan perpustakaan dan metode promosi, tentunya di bidang perpustakaan.

\subsection{Strategi Promosi Perpustakaan}

Kegiatan promosi akan berjalan dengan baik jika didukung dengan adanya suatu strategi. Menurut Dirgantoro (2007) istilah strategi berasal dari kata Yunani yang berarti kepemimpinan dalam ketentaraan. Strategi juga bisa diartikan sebagai suatu rencana untuk mencapai tujuan tertentu. Strategi adalah tindakan potensial yang membutuhkan keputusan manajemen tingkat tinggi dan banyak sumber daya (David, 2008), sedangkan menurut Siagian (2004) menyatakan bahwa strategi adalah keputusan, tindakan dasar 
yang diterapkan oleh semua karyawan organisasi oleh manajemen senior untuk mencapai tujuan organisasi.

Strategi promosi merupakan kegiatan yang direncanakan dengan maksud membujuk, merangsang konsumen agar mau membeli produk perusahaan sehingga tujuan untuk meningkatkan penjualan diharapkan dapat tercapai (Mongi et al., 2013). Dapat disimpulkan bahwa strategi promosi perpustakaan merupakan kegiatan ataupun layanan perpustakaan yang ditujukan kepada pemustaka agar dimanfaatkan secara maksimal dan dapat mencapai tujuan yang diharapkan oleh suatu perpustakaan. Menurut Saiful-Haq (2006) strategi kegiatan promosi yang dapat dilakukan perpustakaan dapat dibagi menjadi empat bagian yaitu program/kegiatan khusus, fasilitas, media dan pemberitaan.

\section{Metode}

Jenis kajian yang digunakan adalah deskriptif dengan pendekatan kualitatif. Lokasi kajian yang dipilih penulis ialah UPT Perpustakaan UMM. Sumber data dalam kajian ini yaitu sumber data primer dan sumber data sekunder. Teknik pengumpulan data yang digunakan adalah dengan wawancara, pengamatan dan studi dokumentasi. Teknik analisis data menggunakan model analisis kualitatif deskriptif (Creswell, 2016). Model analisis tersebut terdiri atas 6 tahap yaitu mengolah dan mempersiapkan data untuk dianalisis, membaca keseluruhan data, men-coding data, tema-tema dan deskripsi, menghubungkan tema dan deskripsi dan menginterpretasikan tema dan deskripsi. Teknik triangulasi yang digunakan yaitu triangulasi sumber, teknik, dan waktu.

\section{Hasil}

Strategi promosi yang dilakukan UPT Perpustakaan UMM pada masa pandemi Covid19 beragam. Kegiatan-kegiatan tersebut berbeda dengan kegiatan promosi yang dilakukan di waktu normal, yang kebanyakan dilakukan secara langsung dan tatap muka. Namun dalam hal ini berbeda, pada masa pandemi Covid-19, strategi promosi UPT Perpustakaan UMM sebagian besar dilakukan secara online. Adapun strategi promosi UPT Perpustakaan UMM antara lain:

\subsection{Program/Event UPT Perpustakaan UMM}

\subsubsection{User Education/Bimbingan Pemustaka}

Bimbingan pemustaka yang dilakukan di UPT Perpustakaan UMM dilakukan secara pribadi maupun kelompok. Bimbingan secara pribadi dilakukan secara langsung kepada pemustaka, baik bimbingan penelusuran koleksi tercetak maupun digital, hingga bimbingan dalam hal temu kembali informasi di perpustakaan. Bimbingan pemustaka secara kelompok dilaksanakan ketika adanya penerimaan mahasiswa baru UMM pada bulan Agustus atau September. Bimbingan pemustaka ini bertujuan untuk memperkenalkan perpustakaan secara keseluruhan, baik koleksi, layanan, fasilitas, sarana dan prasarana, peraturan, penelusuran informasi, peminjaman dan pengembalian, dsb. Bimbingan pemustaka secara kelompok pada masa pandemi Covid-19 dilaksanakan secara online/daring melalui media zoom. 


\subsubsection{Kelas Literasi Informasi}

Kelas literasi informasi UPT Perpustakaan UMM dilaksanakan secara berkelanjutan. Sasarannya yaitu civitas akademika UMM, baik mahasiswa maupun dosen. Pelatihan literasi informasi UPT Perpustakaan UMM dibagi menjadi beberapa paket atau beberapa pilihan materi. Paket 1 berisi materi tentang dasar-dasar literasi informasi dan google form, paket 2 berisi materi tentang penelusuran jurnal dan penelusuran internet dan paket 3 berisi materi tentang mendeley dan plagiarisme. Pelaksanaan literasi informasi pada masa pandemi Covid-19 melaui daring yaitu menggunakan google meet (lihat Gambar 1. Kelas literasi informasi dilaksanakan secara flip classroom, yaitu dilaksanakan dari dua sisi dari offline classroom dan virtual.

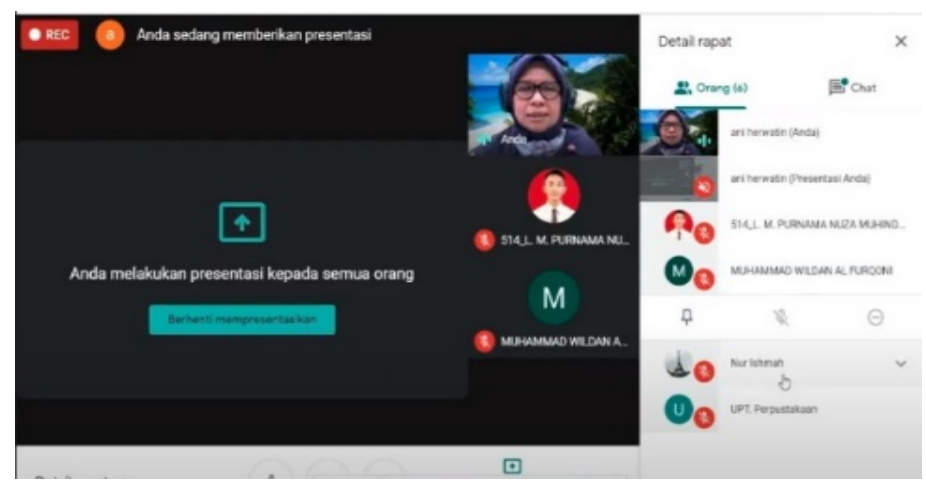

Gambar 1 Kelas Literasi Informasi secara Online di UPT Perpustakaan UMM Sumber: Laporan Kelas Literasi UPT Perpustakaan UMM (2020)

\subsubsection{Seminar}

Masa pandemi Covid-19 tidak membuat UPT Perpustakaan UMM berhenti melakukan kegiatan seminar. Terdapat beberapa seminar yang pernah dilaksanakan UPT Perpustakaan UMM pada masa pandemi, diantaranya yaitu seminar tentang "Urgensi Literasi Informasi dalam Mendukung PJJ Era New Normal" dan "Meningkatkan Produktivitas Prestasi Akademis Melalui Budaya Literasi Informasi (Knowledge Sharing Perpustakaan UMM, UB, dan UM)". Seminar tersebut dilaksanakan secara online/webinar dengan melalui media zoom (lihat Gambar 2) dan live streaming YouTube (lihat Gambar 3). Sasaran dari seminar tersebut diutamakan mahasiswa, selain itu pustakawan dan umum juga diperbolehkan ikut.

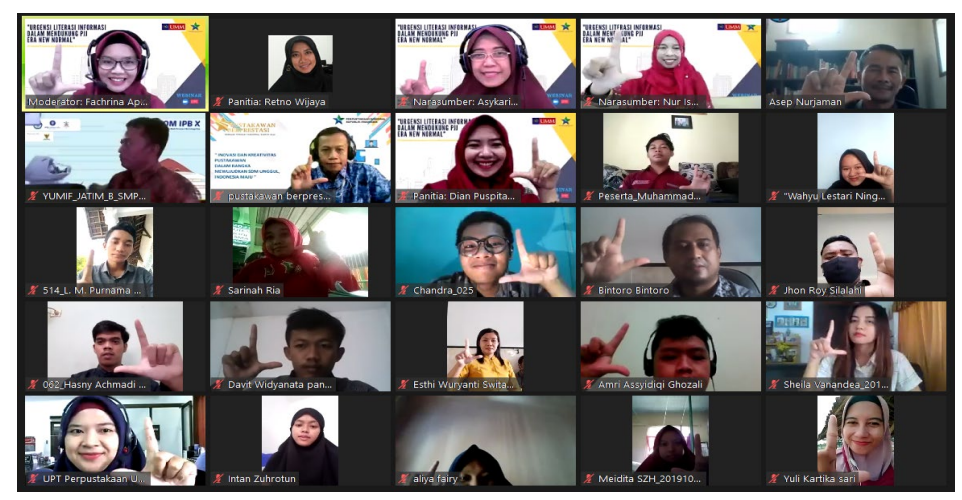

Gambar 2 Webinar UPT Perpustakaan UMM pada Masa Pandemi Covid-19 Sumber: Laporan Kegiatan Webinar UPT Perpustakaan UMM (2020) 

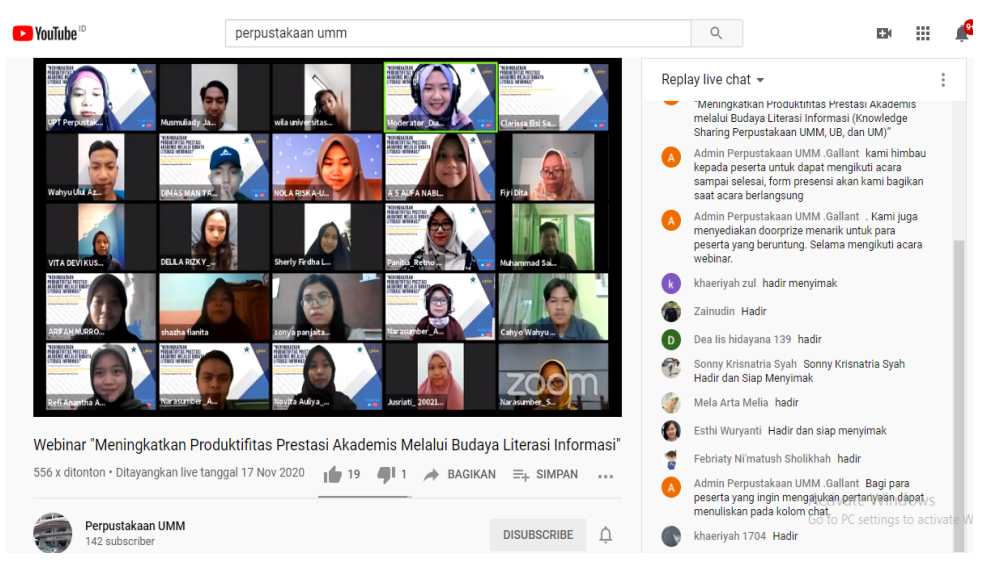

Gambar 3 Webinar UPT Perpustakaan UMM pada Masa Pandemi Covid-19

Sumber: Laporan Kegiatan Webinar UPT Perpustakaan UMM (2020)

\subsubsection{Bedah Buku}

Kegiatan bedah buku UPT Perpustakaan UMM di masa pandemi Covid-19 dilaksanakan sekali dengan tema "Bedah Buku Titik Nadir Penantian". Karya "Titik Nadir Penantian" merupakan refleksi emosi, imajinasi dan cerita kehidupan para perempuan yang terkungkung di jeruji besi Lembaga Pemasyarakatan Perempuan Klas IIA Malang. Kegiatan bedah buku dilaksanakan secara online/webinar dengan melalui media zoom dan live streaming YouTube. Narasumber yang dihadirkan diantaranya Yusri Fajar, S.S., M.A. (Cerpenis dan Dosen FIB UB), Dr. Daroe Iswatiningsih, M.Si. (Kepala Lembaga Kebudayaan UMM), Mariyah, S. Sos., M. Hum (Ketua FPPTI Pusat), Sofian Munawar, MA (Pendiri Yayasan Ruang Baca Komunitas) dan Kurniawan Muhammad (Direktur Jawa Post Radar Malang). Antusias peserta sangat besar sekali, baik mahasiswa, pustakawan maupun masyarakat umum. Hal tersebut merupakan salah satu kegiatan promosi yang efektif.

\section{2 myUMM Library}

UPT Perpustakaan UMM pada masa pandemi Covid-19 menciptakan layanan myUMM Library (lihat Gambar 4). Hal ini dilakukan agar layanan perpustakaan tetap efektif dan efisien untuk dimanfaatkan pemustaka yang tidak bisa berkunjung ke perpustakaan secara langsung.

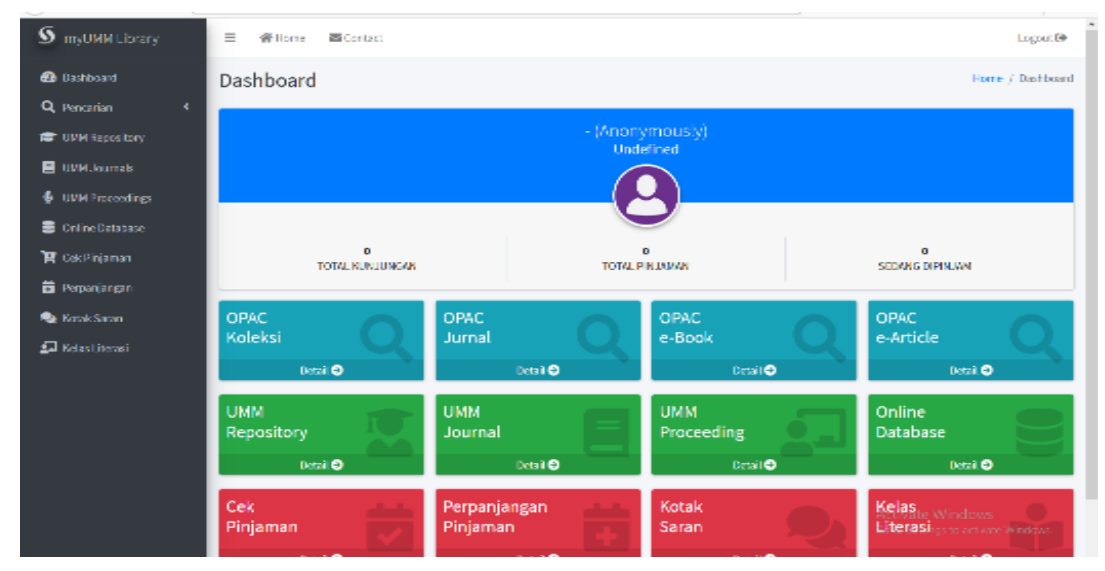

Gambar 4 Tampilan Utama myUMM Library UPT Perpustakaan UMM Sumber: https://laser.umm.ac.id/myummlib/ 
Beberapa menu yang ada di myUMM Library antara lain: koleksi sebagian yang dimiliki UPT Perpustakaan, koleksi yang dimiliki Universitas, dan data pemustaka di Perpustakaan UMM (lihat Gambar 5). Terciptanya myUMM Library memudahkan pemustaka untuk mengakses segala informasi yang dimiliki UPT Perpustakaan UMM di mana pun dan kapan pun selama 24 jam, sehingga mahasiswa yang sedang kuliah di rumah masih tetap bisa mendapat layanan perpustakaan secara online melalui myUMM Library. myUMM Library dapat diakses melalui alamat website https://laser.umm.ac.id/myummlib/.

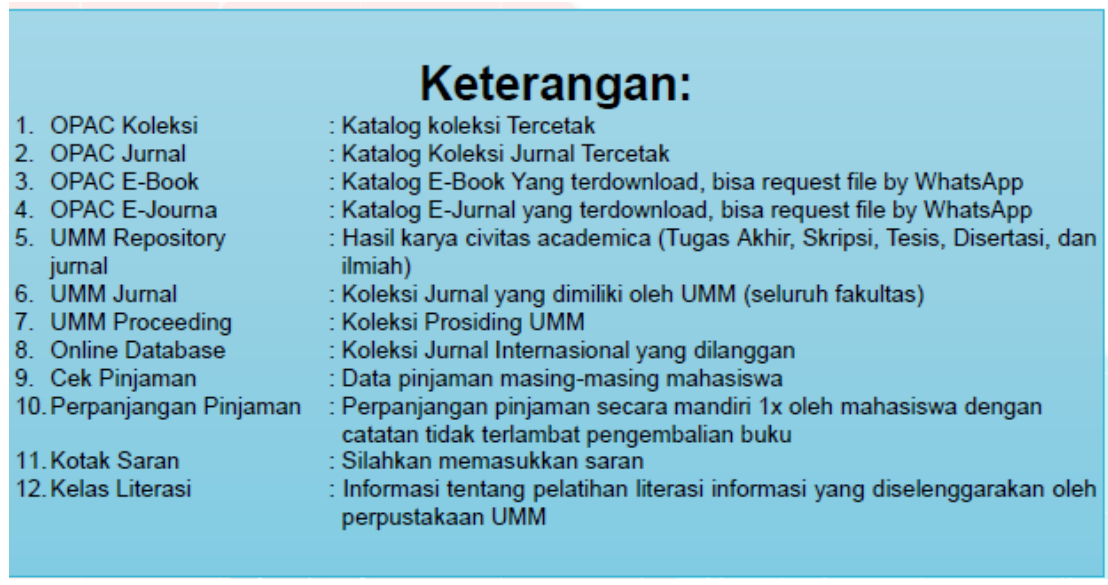

\section{Gambar 5 Penjelasan Layanan myUMM Library UPT Perpustakaan UMM Sumber: https://laser.umm.ac.id/myummlib/}

\subsection{Komunikasi dan Layanan melalui Media Sosial}

Komunikasi dan layanan UPT Perpustakaan UMM pada masa pandemi Covid-19 paling efektif dan efisien melalui media sosial yang dimiliki perpustakaan (lihat Gambar 6). Hal ini dilakukan karena komunikasi dan layanan yang diberikan tidak bisa secara tatap muka langsung di perpustakaan. Media sosial yang dimiliki UPT Perpustakaan UMM meliputi Facebook: Perpustakaan Infopus, Instagram: perpustakaan.umm, WhatsApp: 082132535429, YouTube: Perpustakaan UMM, Email: infopus@umm.ac.id dan Website: lib.umm.ac.id.

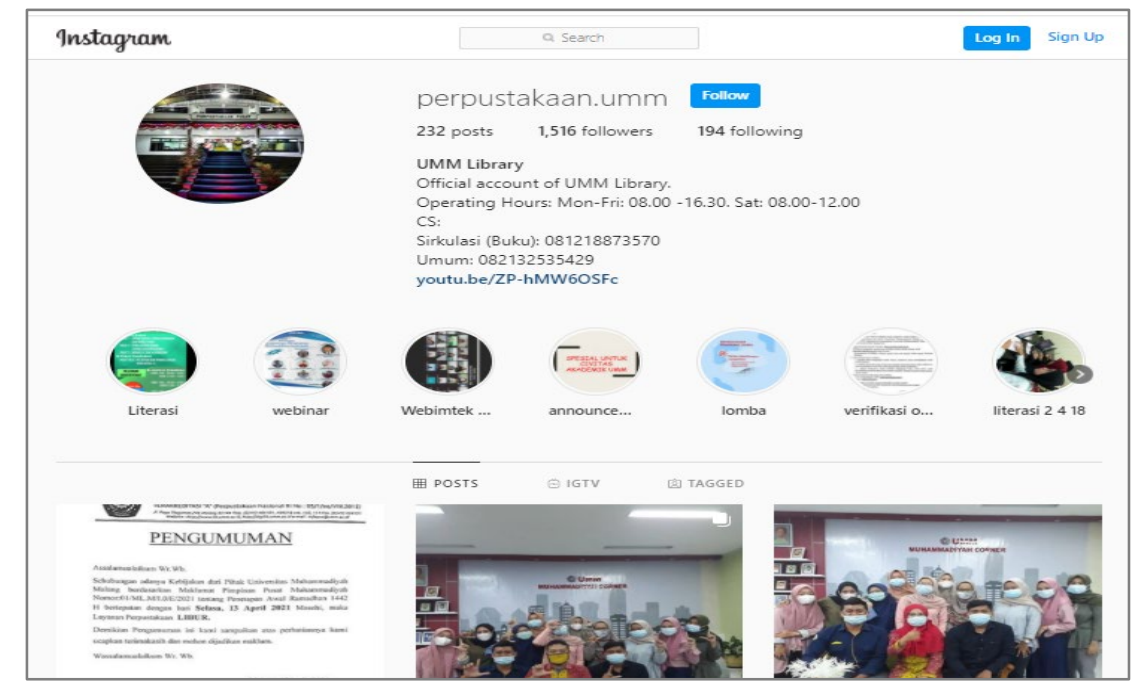

Gambar 6. Media Sosial UPT Perpustakaan UMM Sumber: Olahan Penulis (2021) 
Beberapa media sosial yang digunakan merupakan media promosi yang efektif, yaitu dapat berkomunikasi dan memberikan layanan perpustakaan kepada pemustaka, selain itu juga merupakan upaya untuk menginformasi dan menyebarluaskan segala informasi dan kegiatan-kegiatan yang dilakukan UPT Perpustakaan UMM.

\subsection{Kerjasama Kegiatan Bersama Organisasi Profesi}

Masa pandemi Covid-19, UPT Perpustakaan UMM tetap melakukan kerjasama kegiatan bersama organisasi profesi. Kerjasama tersebut terjalin dengan FPPTI (Forum Perpustakaan Perguruan Tinggi Indonesia) Jawa Timur, dan FPPTMA (Forum Perpustakaan Perguruan Tinggi Muhammadiyah dan Aisyiyah). Beberapa kerjasama kegiatan yang dilakukan pada masa pandemi Covid-19 diantaranya webinar dengan tema "Persiapan Perpustakaan dalam PJJ (Pendidikan Jarak Jauh) Agustus 2020" kolaborasi UPT Perpustakaan UMM dengan FPPTMA (lihat Gambar 7). Selain itu UPT Perpustakaan UMM juga aktif mengikuti beberapa kegiatan yang diadakan FPPTI JATIM, salah satunya yaitu "FPPTI JATIM AWARD: EVALA dan EVALIA 2020" (lihat Gambar 8). UPT Perpustakaan UMM menjadi pemenang Juara 1 dan Juara favorit EVALA serta Juara favorit EVALIA.

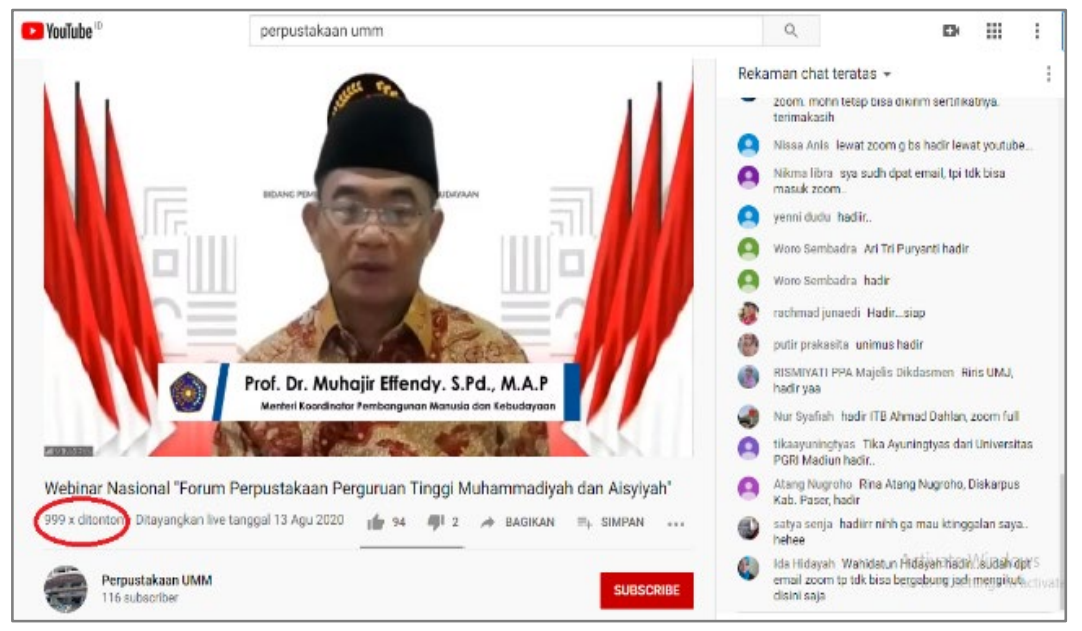

Gambar 7 Webinar Kerjasama UPT Perpustakaan UMM dengan FPPTMA Sumber: Olahan Penulis (2021)

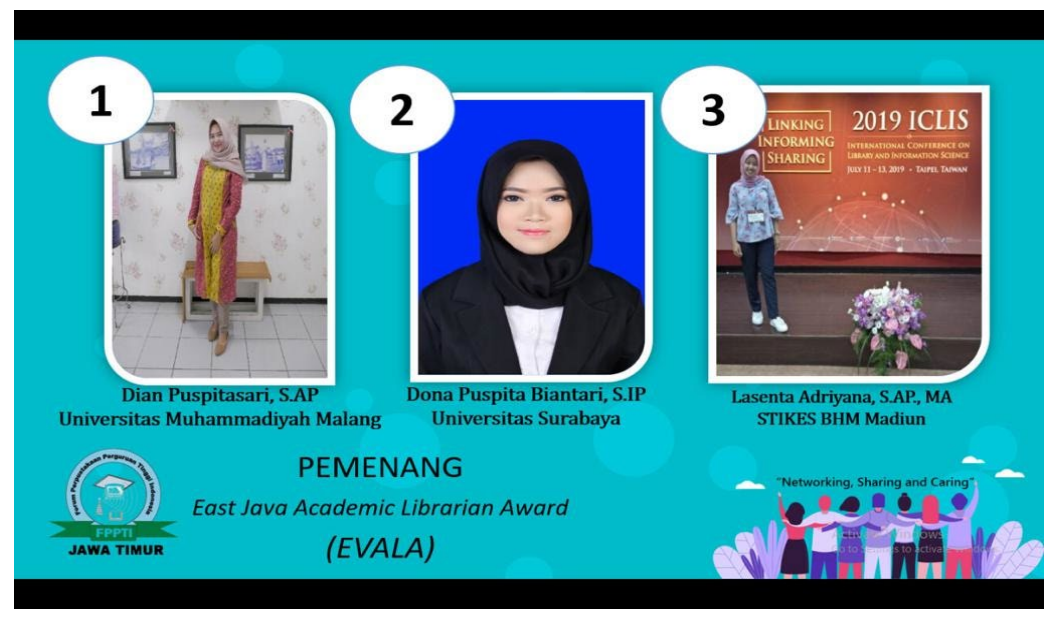

Gambar 8 FPPTI JATIM AWARD: EVALA 2020

Sumber: Olahan Penulis (2021) 
Beberapa strategi promosi yang dilakukan UPT Perpustakaan UMM pada masa pandemi Covid-19 memberikan dampak yang positif. Dampak yang dihasilkan yaitu peningkatan akses digital UPT Perpustakaan UMM.

Tabel 2 Statistik Pengunjung Digital Pada Masa Normal dan Pandemi Covid-19 di UPT Perpustakaan UMM

\begin{tabular}{llllll}
\hline $\begin{array}{l}\text { Pengunjung Digital } \\
\text { Perpustakaan }\end{array}$ & $\begin{array}{l}\text { Bulan Desember } \\
2019\end{array}$ & $\begin{array}{l}\text { Bulan Januari- } \\
\text { Maret 2020 }\end{array}$ & $\begin{array}{l}\text { Bulan April- } \\
\text { Desember 2020 }\end{array}$ & $\begin{array}{l}\text { Bulan Januari- } \\
\text { Maret 2021 }\end{array}$ & Jumlah \\
\hline Normal & 261.609 & 882.310 & - & - & 1.143 .919 \\
Pandemi & - & - & 4.282 .573 & 1.017 .462 & 5.300 .035 \\
\hline
\end{tabular}

Sumber: http://otomasi.lib.umm.ac.id/admin/form-location/

Peningkatan kunjungan digital/akses digital pada masa pandemi Covid-19 menunjukkan bahwa antusias mahasiswa sangat baik dalam akses online dalam penelusuran informasi yang dibutuhkan mahasiswa baik informasi koleksi buku maupun database e-resources yang di langgan perpustakaan dan dapat dikatakan strategi promosi yang dilakukan UPT Perpustakaan UMM berhasil.

\section{Kesimpulan}

Pandemi Covid-19 tidak membuat UPT Perpustakaan UMM berhenti dalam melakukan kegiatan promosi. Strategi promosi UPT Perpustakaan UMM yang dilakukan beragam, membuat program/eventUPT Perpustakaan UMM, diantaranya user education/bimbingan pemustaka, kelas literasi informasi, seminar dan bedah buku. Selain itu, dalam mendukung layanan prima UPT Perpustakaan UMM di masa pandemi Covid-19, perpustakaan menciptakan inovasi baru yaitu myUMM Library. Kegiatan promosi yang lain yaitu komunikasi dan layanan melaui media sosial yang dimiliki perpustakaan dan melakukan kerjasama serta kolaborasi kegiatan bersama FPPTI JATIM dan FPPTMA. Adanya beberapa kegiatan promosi yang dilakukan UPT Perpustakaan UMM memberikan dampak yang positif, yaitu meningkatnya kunjungan digital/akses digital yang signifikan.

Saran yang dapat diberikan terkait kegiatan promosi perpustakaan di masa pandemi Covid-19 diantaranya melakukan kegiatan layanan perpustakaan berbasis online dan dapat melalui media sosial perpustakaan, serta tetap melakukan kerjasama dengan perpustakaan lain secara daring, agar tingkat kepuasan pemustaka tinggi dan kebutuhan informasi pemustaka terpenuhi.

\section{Daftar Pustaka}

Creswell, J. W. (2016). Research Design: Pendekatan Kualitatif, Kuantitatif, dan Mixed. Pustaka Pelajar.

David, F. R. (2008). Manajemen Strategis 2: Konsep(10 ed.). Salemba Empat.

Dirgantoro, C. (2007). Manajemen Stratejik. Grasindo.

Gitosudarmo, I. (2008). Manajemen Strategis. BPFE.

Harsana, L. (2005). Manajemen Perpustakaan. Gaja Mada University press.

Indonesia, D. P. N. (2004). Perpustakaan Perguruan Tinggi: Buku Pedoman.

Martoatmojo, K. (2011). Pelayanan Bahan Pustaka. Universitas Terbuka.

Mongi, L., Mananeke, L., \& Repi, A. (2013). Kualitas produk, strategi promosi dan harga pengaruhnya terhadap keputusan pembelian kartu simpati telkomsel di kota manado. Jurnal Emba, 1(4), 2336-2346. 
Mustafa, B. (2012). Promosi Jasa Perpustakaan. Universitas Terbuka.

Qalyubi, S. (2007). Dasar-dasar ilmu perpustakaan dan informasi. Jurusan Ilmu Perpustakaan dan Informasi (IPI), Fakultas Adab UIN Sunan Kalijaga.

Rahayuningsih. (2007). Pengelolaan Perpustakaan. Graha Ilmu.

Rosa, K., \& Storey, T. (2016). American libraries in 2016: Creating their future by connecting, collaborating and building community. International Federation of Library Associations and Institutions, 42(2), 85-101. https://www.ifla.org/files/assets/hq/publications/ifla-journal/ifla-journal-422_2016.pdf

Saiful-Haq, R. (2006). Pengantar Management Perpustakaan. UIN Syarif Hidayatullah Fakultas.

Siagian, S. P. (2004). Manajemen Sumber Daya Manusia. Bumi Aksara. 